\title{
EDITORIAL
}

\section{Mentors for newly appointed consultants}

\author{
Anne Dean
}

The transition from specialist registrar (SpR) to first consultant appointment can be extremely stressful and demanding. With the period of higher specialist training now relatively short, at only 3 years, it is more crucial than ever to address the realities of this transitional period. On appointment, a new consultant will face, among numerous other pressing issues, a sharp increase in the range and complexity of his or her responsibilities, requests and demands for leadership and professional skills, and the necessity of managing working practice to meet the needs of colleagues, managers and other professionals, and all this in the context of meeting and remembering the names and roles of large numbers of new people within a short space of time.

For these reasons, and in an effort to improve the general morale of psychiatrists in their day-to-day practice, the College recommends that all newly appointed consultants should have access to at least one designated senior colleague - a mentor (or mentors) - to whom they could turn (in person, by telephone or via electronic mail, if preferred) for advice, support or information in these crucial early days. It is, of course, quite possible that the new consultant will not wish to take advantage of such help, but a group of willing consultant psychiatrists should, none the less, be identified in case their support is required. The benefits of this type of support for new consultants could be seen to include not only a reduction in stress and uncertainty at a difficult time, thus maintaining their emotional well-being, but also the opportunity to consolidate and widen their skills effectively and quickly. Such development will, in turn, lead to best practice for both the service and patients.

The College strongly recommends that a list of those willing to take on the responsibility of mentor be drawn up at a local level when the consultant's job description is written and that each division maintain a regional list of such mentors. Mentorship arrangements should be identified before the meeting of the Appointments Committee and, wherever possible, new consultants should be given the names and contact numbers of potential mentors (both internal and external to the trust in which they are working) before taking up their appointments. Assessors on Advisory Appointments Committees (AACs) for all medical specialities are now required to ask about the committees' mentorship arrangements at AACs and, in some trusts, a senior manager (rather than a consultant) is appointed as a mentor to newly appointed consultants. It has also been suggested that, where available, a designated group of recently appointed consultants might be identified as mentors for new appointees.

\section{How mentorship could work}

If desired, the newly appointed consultant should make contact with his or her chosen mentor at an early stage, preferably before taking up his or her post. It is important to stress that mentoring arrangements should be flexible and largely informal, in order to make the process as helpful as possible. Depending on individual circumstances and requirements, the mentor's role could include offering support, advice and guidance; providing help and information on models or working within different management structures, committees and other organisational matters, as required.

The mentor could also help to support and advise the new consultant on other matters. These include: time management; managing and balancing conflicting clinical and management demands; deciding on priorities; delegation; implementing clinical governance; identifying 'key' staff in other organisations and making contact with them; the process of clinical decision-making; obtaining study leave, annual leave, etc.; managing the leadership of the multi-disciplinary team, as well as developing skills to be an effective team player; providing advice on problem-solving; advising on the training and supervision of senior house officers (SHOs) and other trainees and issues relating to continuing

Anne Dean was, until December 2002, the Head of Postgraduate Education Services at the Royal College of Psychiatrists. She is now Assistant Director of The Leverhulme Trust (1 Pemberton Row, London EC4A 3BG, UK). 
professional development (CPD); and encouraging the new consultant to seek advice/guidance from colleagues, local or distant, regarding clinical matters.

\section{Definitions of a mentor}

Mentors could be either from within the trust in which the newly appointed consultant works, or from outside. It is preferable that mentors have been consultants for at least 5 years. Once a mentor has been chosen by the newly appointed consultant, regular meetings should be established during the first 2 years of his or her new post. These might be monthly, but should be by flexible arrangement. If it is felt to be advisable, the mentor should encourage approaches from the new consultant by telephone or in person. The mentor will not have management responsibility for the new consultant, but is appointed to provide guidance and support to enable the new consultant to make the adjustment to his or her new post as smoothly, easily and efficiently as possible.

A prime requirement for a mentor is that he or she is approachable, has good personal management skills and has a practice that inspires confidence. He or she should also be able to demonstrate a flexible approach to the role and should not feel tied to any 'rules'. As well as providing direct support to the new consultant, the mentor could usefully help to identify other potential sources of support, if required. These could include immediate clinical colleagues, the Clinical/Medical Director, regional representatives, the College and the British Medical Association Counselling Service.

It is recommended that mentors should undertake some formal training (preferably organised locally).

\section{Conflicts and problems}

If the mentor has significant concerns about the performance or functioning of the new consultant, the mechanisms already in place should be employed, since such issues are linked with clinical governance structures. For additional guidance, the mentor should refer to Good Medical Practice (General Medical Council, 2001) and act accordingly.

It is important to note that there should be no special requirement that the mentor should alert the new consultant's clinical director to a situation unless serious concerns exist and the new consultant has not responded to advice.

For the most part, mentorship arrangements should be confidential between the mentor and the new consultant and as informal as circumstances permit.

Inevitably, there will be occasions when a mentor and new consultant are not compatible. If this occurs, another potential mentor on the original list should be consulted. Once the scheme has been established, a list of consultants willing to act as mentors should be available from regional representatives and/or the appropriate Faculty or Section within the Royal College of Psychiatrists. All queries regarding mentorship should be directed to the Department of Postgraduate Educational Services at the College.

\section{Further reading}

Creed, F. (1996) How consultants manage their time. Advances in Psychiatric Treatment, 1, 65-70.

Department of Health (1990) Consultant Contracts and Job Plans (HC (90)16). London: Department of Health.

General Medical Council (2001) Good Medical Practice. London: General Medical Council.

Roberts, G., Moore, B. \& Coles, C. (2002) Mentoring for newly appointed consultant psychiatrists. Psychiatric Bulletin 26, 106-109. 